\title{
La información viral. Estudio del caso del cierre temporal de elBulli
}

\author{
Viral information. Case study of the temporary closure of elBulli.
}

\author{
Dra. Yanet Acosta \\ Universidad Camilo José Cela (UCJC), Madrid. \\ myacosta@ucjc.edu \\ Dr. João Canavilhas \\ Universidade da Beira Interior, Portugal. \\ ic@ubi.pt \\ Dr. Vicente Gosciola \\ Universidade do Algarve (UAlg), Portugal. \\ vgosciol@uol.com.br
}

Recibido: 25 de agosto de 2011 Aceptado: 15 de noviembre de 2011

\begin{abstract}
Resumen
Internet y las redes sociales han impulsado nuevas fórmulas de distribución de la información, que han sido aprovechadas especialmente por profesionales del marketing para crear el marketing viral. Sin embargo, estos procesos de redistribución de la información no son ajenos a las noticias periodísticas. En este artículo se investigan las fórmulas virales de difusión de la información, a través del estudio del caso concreto del anuncio del cierre temporal de elBulli, que en un blog de The New York Times (NYT) se dio falsamente como cierre definitivo. El objetivo es conocer los procesos de distribución y las fórmulas para atajar o reconducir este tipo de contagios de noticias o informaciones no contrastadas, o falsas, en aras de la calidad informativa y periodística. La información viral falsa se expande a gran velocidad por la Red, cuando parte de medios con cabecera reconocida, como NYT. El efecto viral se potencia cuando esta información es redistribuida por las agencias de noticias. Desmentir esta información es una acción propia de la comunicación de crisis. En este caso, Ferran Adrià utilizó los medios tradicionales para desmentirla y ofreció una noticia nueva (la creación de elBulli Foundation) para posicionar la información real frente a la falsa en la Red. Y aunque el desmentido hubiese sido más rápido, global y efectivo si el protagonista de la noticia hubiese utilizado además de los medios tradicionales, las redes sociales, su respuesta también surtió efecto en Internet.
\end{abstract}




\begin{abstract}
Summary
Internet and social networking have spurred new forms of information distribution, which have been exploited especially by marketing professionals. However, these processes of information redistribution are no strangers to news reports. This article investigates the viral forms of information dissemination through the announced case of the temporary closure of elBulli. The aim is to determine the distribution processes and the formulas for preventing or redirecting infections such untested, or false, news and information, for the sake of information and journalism quality. Although the viral nature of Internet, this effect is amplified when the information, despite being false, is published by media recognized as The New York Times. The viral effect is enhanced when this information is redistributed by news agencies. Refute this information is an action typical of crisis communication. In this case, Ferran Adrià used traditional media to deny it and offered a new story (elBulli Foundation) to position the real information to the false on Internet and even the denial would have been more rapid, global and effective if the protagonist of the story had been used Social Media in addition to traditional media, his response also had a good effect on the Internet.
\end{abstract}

Palabras Clave: Información viral; marketing viral; comunicación de crisis; Internet; Social Media; elBulli.

Key Words: Viral information; viral marketing; crisis communications; Internet; Social Media; elBulli.

\title{
1. Introducción. La globalización de la información
}

El término omnipresente de la globalización trasciende a todas las parcelas de la vida y del conocimiento humano. Hablamos de globalización económica, política, cultural, de consumo.

Steger (2010: 1) sitúa el nacimiento del término en los años 60, aunque no llegó a la conciencia del público hasta un cuarto de siglo después. De hecho, no se habla de globalización con asiduidad hasta los años 90. Joseph E. Stiglitz, premio Nobel de Economía 2001, dedica un libro a dicha década. The roaring nineties: a new history of the world's most prosperous decade (Stiglitz, 2004) es traducido al español como Los felices 90: la semilla de la destrucción (Stiglitz, 2003).

El ex director del Banco Mundial y el ex consejero económico del presidente estadounidense Bill Clinton, alude al término en multitud de ocasiones como una de las causas de la última crisis económica mundial. lanni también destaca el término y dice que globalización no es, simplemente, la extensión cuantitativa y cualitativa de la sociedad nacional (2006: 159). Desde luego, el asunto ha servido para escribir cientos de páginas y el ganador del Nobel le dedicó al fenómeno aún tres libros más: Globalization and its discontents (2003), Making

Sociedad Latina de Comunicación Social

Facultad de Ciencias de la Información - Universidad de La Laguna

Avenida César Marique, s/n; Campus de Guajara

38071 La Laguna, Tenerife (Islas Canarias - España) 
globalization work (2007), Freefall: America, free markets, and the sinking of the world economy (2010).

Beck añade que la globalización está presente en toda manifestación pública (2008: 15). Significa una salida de lo político "desde el marco categorial del Estado" hacia una nueva retórica que abarca todos los campos de la vida: economía, mercados, competencia, producción, prestación de servicios, finanzas, e información (Beck, 2008: 15). El problema es que con su extensión, esa economía mundial "socava los cimientos de las economías nacionales y de los estados nacionales" (Beck, 2008: 16).

La globalización traspasa fronteras, consigue nuevos mercados, fagocita la competencia local y aumenta la conflictividad en las áreas allá donde llega (Beck, 2008: 22-24).

No obstante, la globalización no sólo tiene un lado amenazador, sino también conciliador. Cuando se habla de la globalización de la información se refuerza el sentimiento de democracia y poder del pueblo que puede estar informado en cualquier momento.

Internet ha potenciado el sentimiento de globalización en lo que se refiere a la difusión de la información en tiempo real a todos los ciudadanos del mundo que cuenten con acceso a la Red.

Sin embargo, hay que profundizar en la calidad de la información que se difunde a través de Internet. ¿Está contrastada? ¿Es posible que al igual que ocurre en el mundo off-line Internet propague rumores boca-oreja?

Steger argumenta que el mejor ejemplo de la globalización de la información es el ataque a las Torres Gemelas de Nueva York. La rígida dicotomía entre lo particular y lo local desapareció para convertirse en lo global (2010: 2). Como explica el autor, el 7 de octubre de 2001, un vídeo de Osama bin Laden dio la vuelta al mundo. No había fechas exactas de su grabación, pero se estimó que había sido grabado dos semanas antes y por supuesto, después del atentado del 11 de septiembre. De la cadena televisiva Al-Jazeera, en Qatar, llegó a todo el mundo en cuestión de dos horas (Steger, 2010: 3).

Lo público y lo mediático extendieron sus radios de acción hasta lugares insospechados. El vídeo de bin Laden fagocitó los telediarios y los ordenadores, vía satélite y vía Internet. La razón es que la globalización rediseña los confines gracias a los medios tecnológicos y de comunicación, e Internet constituye un papel central (Violi, 2008: 39). La red de redes es apertura y ampliación del saber (Violi, 2008: 39). Ofrece información, noticias y fuentes que antes eran inaccesibles y herméticas. Casualmente, Violi (2008: 39) añadía: "Internet puede así revelarse como un potente aliado contra la censura de los regímenes autoritarios, como 
demuestran el caso de China". Volvemos a citar el mayor país asiático, protagonista desde las primeras líneas. Y no es casual.

García-Jiménez (2010: 214) añade que la principal herramienta de la globalización es la "cibercomunicación". Consiste en el contacto e intercambio, instantáneos, entre personas que no tienen relaciones geográficas tradicionales (proximidad, inmediatez, costumbres), pero sí tienen identidades, afinidades e intereses comunes (García-Jiménez, 2010: 214). Antes de Internet, nunca podrían haberse puesto en contacto.

Las fronteras nacionales se eliminan. Ya no hay fronteras "identificadas con facetas geográficas, económicas, políticas y administrativas" (García-Jiménez, 2010: 215). Las nuevas fronteras son transnacionales y transcontinentales y se centran en ideas, costumbres, gustos; cultura. Por eso, supone un reto para los estudiosos de la información y de la comunicación. Algunos ya han dado nombres a estas nuevas fronteras: difusas o duras, territoriales o identitarias, jurídico-políticas, simbólicas, culturales, etc. (García Jiménez, 2010: 215).

Las personas pueden unirse y seguirse con un click o con los 140 caracteres de Twitter. ¿Cómo vamos a hablar entonces de fronteras? La información también las ha superado y su presencia en las redes sociales es el último y más rápido ejemplo. Noguera (2010: 175) explicaba un hecho importante al respecto: la incorporación de la periodista Koro Castellano a la dirección general de Tuenti, la red social más importante de España. Esta profesional había sido directora de Internet en Unidad Editorial, directora gerente de ElMundo.es y presidenta de MediosOn, asociación de los principales medios de comunicación digitales en España (Noguera, 2010: 175).

De los medios a una red social. Castellano apareció en la prensa porque su cambio de trabajo fue noticia. Los periodistas no viven siempre ese cambio y aúnan los dos trabajos, para satisfacción o insatisfacción de sus jefes. Los medios se acercan a las redes sociales, y viceversa. En este caso, para beneficio de los dos. Un beneficio positivo, a priori. El caso del cierre temporal de elBulli nos mostrará que también puede ser negativo.

Sin embargo, antes de llegar ahí, nos centraremos brevemente en los protagonistas: periodistas digitales, de los dos medios, de la prensa y de Internet. Los periodistas que escriben, en papel, en un blog y en su perfil. El nuevo mundo globalizado de Internet permite fenómenos impensables: que su blog tenga más lectores que su texto en papel. Y que sus líneas del blog hayan dado la vuelta al mundo varias veces, con publicación-respuestarectificación, incluso antes de que la noticia primigenia salga impresa en papel.

Sociedad Latina de Comunicación Social Facultad de Ciencias de la Información - Universidad de La Laguna

Avenida César Marique, s/n; Campus de Guajara 38071 La Laguna, Tenerife (Islas Canarias - España) 
Noguera (2010: 176) explica que esto puede suponer un peligro para el medio.

En junio de 2009, la agencia de noticias Associated Press (AP) mandó un comunicado a sus periodistas con instrucciones acerca de cómo debían actuar en las redes sociales. La reputación digital está unida a la reputación tradicional, y AP quería controlar los muros de Facebook de sus empleados, sus afiliaciones e intereses políticos, y evitar, sobre todo, que adelantaran noticias en Twitter (Noguera, 2010: 176). Poco después, The Washington Post imitó esta idea con una guía sobre precauciones y estrategias que debían tomar sus periodistas al trabajar con Facebook, LinkedIn, MySpace, Twitter u otras redes sociales (Noguera, 2010: 176).

Todo lo anterior enlaza con una idea muy sugerente de Bacallao (2010: 114), que defiende que las TIC (Tecnologías de la Información y Comunicación) han tenido dos etapas de vida muy distintas: optimismo y pesimismo. Dejamos al lector que sitúe, en uno u otro lado, todos los fenómenos que hemos citado hasta ahora.

Sin embargo, fue el diario The New York Times el primero que animó a sus periodistas a formar parte de las redes sociales y el primero en crear un nuevo puesto dentro de la ahora ciber-redacción: el Social Media Editor. La responsable de este nuevo cargo, erigido en mayo de 2009, fue Jennifer Preston. Desde ese año hasta la actualidad más de doscientos periodistas del diario estadounidense participan activamente en las Redes Sociales, con el objetivo de dar mayor difusión a los contenidos del diario (http://www.nytimes.com/twitter).

La globalización está llena de potencialidades, positivas y negativas según se empleen. Es un panorama complejo, interesante y vivo. Lo público y lo privado se cruzan más que nunca. El periodista crea noticias de formas múltiples y llega a todo el mundo, quiera o no. Mientras, los lectores pueden saberlo todo y en su afán por estar informados, olvidan exigir la credibilidad.

En este artículo nos centraremos en estudiar un caso de información no contrastada, como fue dar por definitivo el cierre temporal de elBulli y cómo se propagó por la Red como si de un virus se tratase. Los resultados del estudio de este caso concreto, por su importancia e implicación de los medios de comunicación de todo el mundo, se pueden trascender como ejemplo de cómo funciona la información viral verdadera, falsa o no contrastada y los métodos para desmentirla como método de comunicación de crisis. 


\section{La naturaleza viral de Internet. El marketing viral}

Una de las marcas distintivas de Internet es su potencial para conectar personas en tiempo real, independientemente de la distancia entre sí. Hasta aquí no hay novedad con relación al teléfono, pero todo cambia cuando verificamos que Internet es un medio de comunicación en el que la información circula en un flujo continuo, de forma sincrónica o asincrónica y con modelos emisión/recepción de uno para uno, de uno para muchos, de muchos para uno y de muchos para muchos (Morris \& Ogan, 1996).

Este modelo comunicacional descentralizado y fragmentado se desarrolló sobretodo en la llamada web 2.0, con la emergencia de herramientas como Blogger, Youtube y, más tarde, de las redes sociales como Facebook o Twitter. Todo este nuevo ecosistema ha dado origen a una inteligencia colectiva, "una inteligencia repartida en todas partes, valorizada constantemente, coordinada y movilizada en tiempo real" (Lévy, 2004, s/n) que está en permanente cambio motivado por los intereses de las comunidades virtuales (Rheigold, 1993). Son los intereses comunes y el flujo informativo bidireccional y permanente que impulsan la información para que circule de una forma rápida entre usuarios.

He aquí la naturaleza viral de Internet, de la que el marketing se ha aprovechado impulsando su capacidad para reproducir un mensaje exponencialmente.

El marketing que aprovecha herramientas concretas para conseguir este efecto viral se reproduce a partir de intereses comunes en las redes sociales online. Sin embargo, debemos tener en cuenta una cuestión ya clásica: "igual que puede ser una manera de obtener éxito, el marketing viral también puede conducir al desastre" (Jaffe, 2005: 64). Esta idea justifica, por sí sola, todos los estudios sobre el marketing viral.

El término se refiere a los efectos de la repercusión rápida de noticias, publicadas en un proceso similar al boca-a-boca (Jaffe, 2005: 200). En el caso de una reproducción de la información entre amigos o conocidos, ofrece mayor credibilidad, sea su origen verdadero o falso. Realmente, el marketing viral digital aún está en proceso de invención (Jaffe, 2005: 218).

Sin embargo, el efecto viral presenta una ventaja enorme con relación al boca-a-boca: puede desconocerse el origen, pero el mensaje no sufre cambios desde el origen hasta el usuario final porque se transmite siempre el mismo contenido. En el boca-a-boca cada persona añade algo. 
Así, en el caso elBulli, que se estudiará con detenimiento posteriormente, el mensaje sufre cambios por intervención directa del cocinero y no por los usuarios que reproducen el contenido equívoco del Blogger de The New York Times.

El mundo del marketing ha visto rápidamente este potencial, que se conoce, aunque su fin final sea impredecible, ya que se debe al contexto en el momento en que se libera el mensaje, al público receptor, y a sus propagadores.

Se trata de movimientos que articula, en las palabras de Don Tapscott y Anthony D. Williams, la gente para generar información. Objetos y dispositivos convergentes, y publicidad de muchos a muchos en un proceso viral (Tapscott \& Williams, 2007: 44). Dejamos esto como una idea para emprender futuros estudios, sólo cuando la teoría cuántica sea utilizada para explicar los efectos de las redes sociales.

Los productos de moda y el marketing viral son algunos de los vehículos de marketing más potentes y eficaces, ya descubiertos. La diferencia entre ellos es que el marketing viral es la promoción de una empresa, de sus productos o de sus servicios, a través de un mensaje persuasivo. Está destinado a ser liberado, por lo general, en línea, de persona a persona, o a través del buzz marketing (o "marketing de zumbido").

Esta última forma es la promoción de una empresa a través de iniciativas concebidas y diseñadas para hacer que la gente y los medios de comunicación hablen positivamente de la compañía, producto o servicio (Kimmel, 2010: 214). Sin embargo, esa positividad también puede ser negativa. La potencialidad de Internet hace que, muchas veces, no podamos prever los resultados. Entre el optimismo y el pesimismo, como decía Bacallao (2010: 114), y recordábamos anteriormente.

\section{El funcionamiento de la información viral}

Alllan J. Kimmel (2010: 251-253) recuerda una campaña del champú Fabergé, emitida en la década de 1970 (disponible en http://www.youtube.com/watch?v=TgDxWNV4wWY). En ella, una chica recomienda el producto a dos amigos. Cada uno de ellos se lo recomienda a otros dos amigos. $Y$ así sucesivamente, mientras la pantalla se divide en varias partes, siempre con imágenes de la primera protagonista. Éste es un buen ejemplo de lo que sería el marketing viral y de la potencialidad de la comunicación boca-a-boca.

El marketing viral se considera una campaña de promoción destinada a ser difundida de forma exponencial. Se dirige a una audiencia deseada y bien definida, ya que anima a la gente a compartir el mensaje de marketing con los demás. De hecho, el término "marketing

Sociedad Latina de Comunicación Social Facultad de Ciencias de la Información - Universidad de La Laguna

Avenida César Marique, s/n; Campus de Guajara 38071 La Laguna, Tenerife (Islas Canarias - España) 
viral" también destaca en la época de la burbuja económica de Internet. Esto es así porque cualquier actividad de marketing acelera y mejora la comunicación por el boca-a-boca, también en la red digital. Con la mejora de la red inalámbrica, las aplicaciones virales comenzaron a migrar a los dispositivos portátiles. Se extendieron, y se extienden aún hoy, con la misma facilidad que la explosión de una campaña de boca-a-boca. Comúnmente es llamado "marketing viral móvil".

Kimmel (2010: 257) también afirma que el marketing viral es capaz de propagarse rápidamente a través de un mensaje, de una población amplia y diversa de los consumidores en el mundo digital. Puede ser manipulador, por estar en peligroso equilibrio entre la realidad y la ficción. La influencia del boca-a-boca, por el contrario, es más eficiente en las comunidades más pequeñas y claramente delineadas por la transmisión de información a una velocidad más lenta. Alí tiene un efecto más duradero, porque se basa en los testimonios personales de los que la propagan. En general, en estos propagadores-usuarios se deposita un mínimo de confianza y de reciprocidad.

Asimismo, Kimmel (2010: 257-261), enumera tres ejemplos clave del marketing viral. Recuerda el primer ejemplo, de 1998. Steve Jurvetson, el principal inversor de capital riesgo en Hotmail, lo practicó con una idea simple: añadir al final de su e-mail la frase "Haga su libre e-mail a [http://www.] Hotmail[. com]". El impacto viral trajo, en un plazo de 18 meses, más de 12 millones de nuevos usuarios. En este caso, el marketing viral fue altamente beneficioso.

En 2003, la marca Honda, con la intención de mejorar su imagen en Reino Unido, promovió una campaña original: La Cog (disponible en http://www.youtube.com/watch?v= ve4M4UsJQo). Es un vídeo de dos minutos de duración y se estima que su producción costó más de seis millones de dólares, con varios meses de trabajo. En él, aparece un efecto dominó, hecho con las múltiples partes de un coche.

Se genera una reacción en cadena, como una "máquina de Rube Goldberg". El único sonido es el que proviene de las partes cuando chocan o se desplazan, a excepción de los últimos veinte segundos cuando una pieza acciona el estéreo de 16 altavoces. De repente, se escucha una música instrumental muy rítmica y un orador concluye con la frase siguiente: "¿No es genial cuando las cosas funcionan?".

No hay otro texto en todo el anuncio, verbal o escrito, a excepción del nombre del modelo y de la marca del coche. El vídeo se emitió por televisión y en la página Web oficial de la compañía. Quería transmitir que todo sucede en tiempo real, sin gráficos ni artificios hechos por ordenador. La idea se propagó como un virus ya que, aunque parezca imposible, las

Sociedad Latina de Comunicación Social Facultad de Ciencias de la Información - Universidad de La Laguna Avenida César Marique, s/n; Campus de Guajara 38071 La Laguna, Tenerife (Islas Canarias - España) 
imágenes no dejaron ninguna duda de su verosimilitud. Como resultado, Honda batió récord de ventas en el primer trimestre de 2004.

Otro ejemplo emblemático es Google que, también en 2004, decidió lanzar su servicio de correo electrónico, Gmail. Identificó e invitó a mil personas, consideradas líderes de opinión, a utilizar el nuevo servicio. Ofrecía una capacidad de mil megabytes por cuenta. Cada uno de los invitados pudo reenviar la invitación a otros usuarios y el gigante de Internet obtuvo una propagación "epidémica" y gratuita gracias a las recomendaciones. En total, se generaron más de tres millones de nuevas cuentas, sólo en tres meses.

Justin Kirby (2006: 96-97) añade que el marketing viral tiene una primera fase de planificación que consiste en: establecer los objetivos de la estrategia de una campaña viable y una idea viral, con la historia y el tema que puede generar el buzz, zumbido o comentario. Después, la campaña tiene tres etapas fundamentales: creación (desarrollo y producción del agente viral que lleva el mensaje que se extendió en formato digital), propagación (distribución de una historia por un buzz y un agente viral, en varios lugares, y con personas que ofrezcan el mayor potencial de influencia y difusión) y detección (medición de los resultados de la campaña para la rendición de cuentas y la evidencia de éxito o no).

Explica que el éxito puede lograrse por los siguientes factores: planificación estratégica para asegurar que el marketing viral lleve a conocer los beneficios tangibles y mensurables de la marca, proporcionar material adecuado para el factor boca-a-boca a los usuarios, y propagación específica para un buzz o comentario, en los lugares donde personas influyentes se reúnen para difundir el viral y la marca.

Pero no siempre una acción viral resulta de una maniobra de marketing. A veces la rápida propagación de determinada información tiene relación con la dimensión del acontecimiento o la importancia de la fuente de la información en las comunidades virtuales. Nos centramos en la fuente de información porque es lo que interesa en este caso, y en dos figuras: la fuente primaria y el redistribuidor de la información.

En el primer caso hablamos de personajes implicados en el caso y que haden cumplir un conjunto de particularidades como credibilidad, autoridad, accesibilidad, disponibilidad o productividad (García Santamaría, 2010). Como se verá adelante, en este caso la credibilidad del periódico asociado, la autoridad del autor y la accesibilidad del soporte han sido cruciales en la forma como el caso se desarrolló.

En el caso de la redistribución debe destacarse que en un medio donde proliferan las fuentes informativas, como Internet, la economía de la atención asume un papel fundamental. La ccuestión ya nos es qué información tengo sino que información puedo consumir en el

Sociedad Latina de Comunicación Social

Facultad de Ciencias de la Información - Universidad de La Laguna

Avenida César Marique, s/n; Campus de Guajara

38071 La Laguna, Tenerife (Islas Canarias - España) 
tiempo de que dispongo. Aquí entra la figura del gatewatcher (Bruns, 2003), un elemento influyente y legitimado por la comunidad cibernética a quien se les dan el privilegio de indicar las informaciones más destacadas colgando enlaces en su mural de redes sociales o en un post publicado en su blog. Es este caso, el impulso viral funciona como en el caso del marketing viral, pero sin objetivos estratégicos de una marca.

Por todo lo anterior, podemos aclarar que no es una técnica muy utilizada en nutrición y gastronomía. Los consumidores quieres estar bien informados de lo que comen y beben. Sí se fían del boca-a-boca pero tienen que probarlo todo por sí mismos.

En cambio, informarse y opinar en gastronomía es más banal, apetecible y barato. Veremos que las informaciones, los rumores y las noticias no contrastadas funcionan más rápidamente como marketing viral, que una crítica de un restaurante.

\section{Metodología de estudio}

Después de explicar brevemente los conceptos de globalización, marketing viral e información viral, podemos adentrarnos en el caso que aquí nos importa. Pretendemos hacer un estudio del caso acerca de la noticia del cierre temporal de elBulli. Ese cierre temporal es la noticia real y final. Todas las noticias y rumores que la precedieron funcionaron como información viral, negativa para el restaurante y para el chef, Ferrán Adrià. Para demostrarlo, planteamos la investigación desde tres ámbitos:

a) Investigación Iongitudinal: Estudio de todas las noticias sobre elBulli y sus propietarios, en la prensa nacional e internacional, a lo largo del año 2010.

b) Análisis de contenido de esas noticias: qué periodistas las firmaban, en qué medios aparecían, en qué página o de qué forma, y su presencia en redes sociales.

c) Análisis del caso: A través de los puntos a) y b) podemos hacer un análisis cualitativo y cronológico del caso para establecer los antecedentes, las diferentes vías que tomó la información, y los resultados negativos y positivos, para el restaurante y sus propietarios.

Validamos estos tres ámbitos con las reflexiones siguientes:

a) El caso del cierre temporal de elBulli es un ejemplo, a priori, de marketing e información viral. Las primeras noticias obligaron a Ferrán Adrià a anunciar lo que reservaba para meses más tarde. 
b) El caso que presentamos también es un caso real de globalización. La gastronomía española está presente en todo el mundo y la noticia funcionó de manera internacional. Demuestra que vivimos en una sociedad global, que debe ser objeto de estudio de las Ciencias Sociales (Ianni, 2006: 162).

c) Toda investigación longitudinal tiene su comienzo en un "incidente crítico". Este término, acuñado por el psicólogo estadounidense J.C. Flanagan, es rescatado por López-Galiacho como una actividad humana observable y cualitativa, que permite descubrir "hechos, relaciones y vinculaciones relevantes y hasta entonces desconocidas" (2010: 222). En este caso, el incidente crítico es una noticia falsa sobre elBulli, que desencadena una fiebre informativa con noticias reales, falsas, inventadas, mal interpretadas, positivas y negativas; y por ende, noticias que provienen de los propios protagonistas de la noticia y que acaban por ser emisores para evitar más información viral. Como en todo incidente crítico, hay que detectar los roles de los participantes internos y externos (López-Galiacho, 2010: 222). Serán los propietarios del restaurante y todos los periodistas que escribieron sobre el asunto.

\section{El caso del cierre temporal de elBulli}

La información gastronómica ha sido protagonista de muchas contraportadas de diarios de información general y económica; y de portadas de suplementos dominicales y de ocio de la prensa diaria. No obstante, encontrarla en una portada de los diarios no fue un hecho hasta el anuncio, el 26 de enero de 2010, durante la celebración del congreso Madrid Fusión, del cierre temporal de elBulli durante dos años.

Tras el anuncio por parte de Ferran Adrià en una multitudinaria conferencia de prensa, los informativos televisivos hicieron conexiones especiales y los medios en Internet propagaron con celeridad la noticia. Al día siguiente, se publicó en la primera página de la gran mayoría de los diarios en papel españoles e incluso en uno internacional, el Financial Times.

\section{El impacto mediático tras el anuncio del cierre durante dos años de elBulli, el 26 de enero de 2010}

Los dos diarios de información general de mayor tirada en España anunciaron en portada el cierre temporal de elBulli, en sus ediciones del 27 de enero de 2010. En El País ocupó la banda superior y se acompañó de una foto. El titular fue "El fogón de elBulli se apagará dos

Sociedad Latina de Comunicación Social Facultad de Ciencias de la Información - Universidad de La Laguna

Avenida César Marique, s/n; Campus de Guajara 38071 La Laguna, Tenerife (Islas Canarias - España) 
años". El texto completo, firmado por la periodista gastronómica Rosa Rivas, se publicó en una página de la sección de "Cultura". Se acompañó de la opinión del crítico gastronómico.

En El Mundo, la noticia se publicó en la banda derecha de la portada con una fotografía. El texto, firmado por Adrián Cornejo, el periodista que cada año cubre el Congreso Internacional Madrid Fusión, en el que se hizo el anuncio, se incluyó en la sección de "Cultura" y ocupó dos páginas bajo el titular "elBulli cierra sus puertas durante dos años".

La noticia también fue portada de La Razón, pero no de $A B C$, ni Público, ni los diarios económicos Expansión y elEconomista. Sí fue portada de Cinco Días, pero el titular fue bien distinto a la tónica general, ya que en la primera página no se hacía referencia al cierre, sino a la situación económica del restaurante. Se tituló: "elBulli redujo en dos años su beneficio a la mitad". Esta información no fue ofrecida durante la rueda de prensa, pero tampoco se identificaba la fuente en el texto.

La noticia, firmada por la periodista Paz Álvarez, explicaba en páginas interiores de la sección "Empresas", además del anuncio del cierre y los detalles de la situación económica del restaurante, la reacción de Francia ante el anuncio, donde se achacaba a la presión que sentía el cocinero con la Guía Michelin y a una posible operación de marketing. Para otros diarios como La Vanguardia, El Punt, Diari de Girona y El Periódico, fue la noticia más importante del día, y le dedicaron la mitad de su primera página.

Los diarios internacionales se hicieron eco de la noticia. Pero fue el diario económico británico Financial Times, el que la sacó a portada. En su primera página, publicó una fotografía de Ferran Adrià, de $12 \times 18$ centímetros, que colocó en la parte de mayor importancia de la portada; a la derecha, con un pie a tres columnas. En el texto se indicaba que elBulli cerraría por dos años, desde 2012, y que el chef más conocido y admirado del mundo comenzaría una nueva etapa tras este cierre. En el texto interior, escrito por Victor Mallet desde Madrid y publicado en la página 4 del diario, se explicaba que se trataba de una decisión personal del cocinero y calificaba el anuncio como "traumático".

Al día siguiente, 28 de enero, los diarios de todo el mundo continuaron publicando la noticia, como el Times of India, que titulaba: "Chef tired, best eatery to shut for 2 years" ("El chef se cansó, el mejor restaurante cerrará dos años").

También los diarios nacionales continuaron hablando del anuncio, dedicando reportajes, análisis y columnas de opinión. El Periódico publicó en contraportada una entrevista en exclusiva con el cocinero, quien inicialmente, durante la rueda de prensa, había indicado su negativa a ofrecer entrevista alguna. Tras esta entrevista, fueron apareciendo otras en el resto de diarios. El 29 de enero, elEconomista (que anteriormente no había sacado el tema a

Sociedad Latina de Comunicación Social Facultad de Ciencias de la Información - Universidad de La Laguna

Avenida César Marique, s/n; Campus de Guajara 38071 La Laguna, Tenerife (Islas Canarias - España) 
portada) publicaba en su primera página con foto la entrevista con el cocinero en la que destacaban: "Con elBulli perdía dinero". La entrevista, firmada por el periodista que habitualmente escribe de gastronomía en el diario, Juan Manuel Barberá, se incluyó en la sección "Gestión Empresarial".

El sábado 30 de enero, las entrevistas, los análisis y los artículos de opinión sobre el cierre de elBulli, así como las reacciones de los cocineros, continuaron apareciendo en la prensa diaria nacional. Además, el acontecimiento continuó siendo portada. Así, La Razón dedicó la franja superior de su primera página a anunciar una entrevista publicada en la sección de "Cultura" firmada por la periodista gastronómica Tatiana Ferrandis y que titulaba "El nuevo Bulli no será restaurante".

Ese mismo día, Cinco Días publicaba una nueva información sobre el restaurante firmada por la periodista Paz Álvarez, en un tono distinto a la publicada el 27 de enero. En ella ya no hablaba de las cuentas de elBulli, sino de que el parón estaba motivado para conseguir impulsar la creatividad. La noticia se publicó en el suplemento "Empleo y directivos" del diario y se tituló "Parar para renacer".

El diario francés Le Monde publicó el 30 de enero la noticia titulada "Mauvaise passe pour El Bulli" ("Mal paso para elBulli"), en la página 23 de su sección "Cultura". En ella, el periodista Jean Claude Ribaut aseguraba que el verdadero motivo del cierre del restaurante era la aceleración del proceso iniciado por los hijos de un antiguo socio de Adrià, Miquel Horta, por el que se le reclamaban 12 millones de euros.

El diario adjudicaba la información al abogado de la familia supuestamente demandante, pero no incluía ninguna declaración del chef sobre este asunto. De hecho, preguntado por el tema, Adrià ha asegurado que nunca ha recibido demanda alguna por parte de esta familia. En el artículo de Le Monde se recordaba además la denuncia del autor alemán Jörg Zipprick. Éste manifestaba la supuesta utilización, por parte del cocinero español, de aditivos en sus elaboraciones culinarias, que podrían ser dañinos para la salud.

El domingo 31 de enero, todos los diarios volvieron a retomar el asunto con artículos, reportajes y entrevistas. El 1 de febrero, El Mundo dedicaba nuevamente su portada a Adrià, tan solo cinco días después de haberlo sido. La portada anunciaba una entrevista con el chef, escrita por el periodista y crítico gastronómico Xavier Agulló, que se incluyó en la sección de "Cultura" (páginas 38 y 39). Se tituló: "Ferran Adrià: ni estaremos en el circuito ni habrá estrellas Michelín".

Sociedad Latina de Comunicación Social Facultad de Ciencias de la Información - Universidad de La Laguna Avenida César Marique, s/n; Campus de Guajara 38071 La Laguna, Tenerife (Islas Canarias - España) 
El País también repitió portada con elBulli el 3 de febrero, una semana después del anuncio. La entrevista, firmada por David Fernández, fue titulada "Yo también necesito parar" y ocupaba una doble página de la sección de "Cultura".

La noticia del cierre de elBulli parecía ya suficientemente comentada y tratada por los diarios nacionales e internacionales a principios de febrero, hasta que el 12 de ese mes, el blog del periodista Andrew Ferren, adscrito a The New York Times publicó un post titulado "elBulli cerrará permanentemente". En pocos minutos, dio la vuelta al mundo a través de la red y convulsionó a gran parte de la opinión pública. El problema fue que la noticia no era exacta. No había ninguna novedad, elBulli cerraría, sí. Pero por dos años, tal y como ya había anunciado el jefe de cocina en enero. Todo, según el cocinero se debió a un malentendido lingüístico, que provocó un aluvión de noticias.

\section{Un efecto viral. Confusiones y desmentidos en torno al cierre de elBulli}

Tras la publicación en el blog "Diner's journal", asociado al diario The New York Times, el 12 de febrero a la 6.33 pm hora de Estados Unidos, la noticia del cierre permanente de elBulli se creó un efecto viral que se contagió por todos los medios de comunicación y blogs en la red. A diferencia del conocido como marketing viral, este efecto con una noticia no tiene, a priori, una estrategia, ni tiene una motivación específica (Wilson, 2005). Sin embargo, la forma de funcionamiento es similar, ya que se basa especialmente en dos conceptos: el formato adecuado y la publicación en el lugar idóneo adonde se llega a líderes de opinión mundiales (Sivera, 2008: 83).

El formato fue el de noticia con fuente Ferran Adrià y el lugar de publicación, un diario que se considera uno de los más potentes prescriptores de opinión, pese a que no se trataba de las páginas específicamente del periódico sino de uno de sus blogs. Además, hay que añadir el día de su publicación, justo en fin de semana. Esto complicaba la localización de la fuente para contrastar la información.

El efecto de esta noticia viral fue similar al que se provoca con el marketing viral. Aunque en este caso, al ser una noticia falsa, el efecto fue nocivo. Además, pese a que se desmienta lo publicado inicialmente, el impacto no es el mismo que el provocado en un primer momento. En la mente de muchos lectores, así como en las búsquedas a través de Internet, queda la noticia inicial.

El efecto viral del post de este blog fue impulsado al día siguiente, 13 de febrero, por la publicación de un teletipo de la Agencia Efe en el que se informaba de lo publicado por el bloguero y que se adjudicaba directamente a The New York Times. De esta manera, se llegó

Sociedad Latina de Comunicación Social

Facultad de Ciencias de la Información - Universidad de La Laguna

Avenida César Marique, s/n; Campus de Guajara

38071 La Laguna, Tenerife (Islas Canarias - España) 
exponencialmente a muchos más líderes de opinión de la blogosfera y de los medios de comunicación convencionales. La Agencia Efe cometió el error deontológico de no contrastar la noticia con la fuente afectada, motivo por el que posteriormente tuvo que publicar una nota de corrección. Aunque lo hizo al día siguiente, 14 de febrero.

Esta nota de corrección de la Agencia Efe se reprodujo en las ediciones digitales de algunos medios. No obstante, los diarios nacionales en papel optaron por hacer uso de sus periodistas especializados en gastronomía para contrastar la información con la fuente afectada, Ferran Adrià. La facilidad de acceso a las fuentes y el conocimiento del tema son claves en esta situación en la que se produce una infección viral.

El chef, por su parte, se vio obligado a adelantar a estos periodistas el anuncio de que el restaurante se convertiría en una Fundación. De esta manera, se puede considerar que los periodistas especializados actuaron como cortafuegos de la noticia viral, como dejaron patente especialmente en las ediciones de los principales diarios publicadas el 14 de febrero. La noticia fue publicada por los periodistas gastronómicos de El País, El Mundo, La Vanguardia y $A B C$, entre otros, en la edición del domingo 14 de febrero.

La corrección por parte del bloguero de The New York Times no apareció hasta el 15 de febrero y se publicó como un post de su blog. Al día siguiente, 16 de febrero, uno de los cocineros más emblemáticos de Estados Unidos, Grant Achatz publicó en el diario en papel una carta homenaje a elBulli. En esta carta, confirmaba que el considerado mejor restaurante del mundo no cerraría permanentemente.

\section{Figura 1: Noticias publicadas sobre elBulli.}

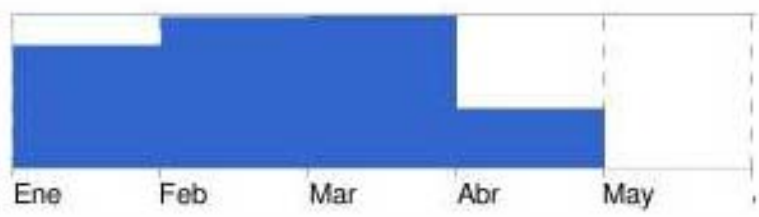

Fuente: Google News. 
El impacto mediático de esta serie de las noticias confusas y de los desmentidos se puede observar gráficamente acudiendo al seleccionador de noticias del buscador Google. Como puede verse continuación, el periodo de mayor aparición de noticias con referencia al restaurante elBulli fue, paradójicamente, el de los meses de febrero y marzo, pese a que el anuncio del cierre temporal se realizó en enero. El estudio se ha realizado hasta el 4 de mayo de 2010 y el gráfico siguiente procede de http://news.google.es.

\section{Un calendario de hechos. La explicación del protagonista, Ferran Adrià}

En una entrevista personal concedida a los autores, Ferran Adrià asegura que se vio obligado a adelantar el anuncio de la creación de una Fundación, debido a la presión que sufrió tras la publicación de la nota errónea por parte del bloguero de The New York Times. El chef relata que la noticia errónea se debió únicamente a un error. La entrevista fue realizada por el periodista de The New York Times, a través del teléfono. Era la noche de un viernes y Adrià estaba cenando. Asegura que, en otra ocasión, le hubiese enviado un mail con la información. Pero dio por acabada la conversación y, según él, sus palabras fueron malinterpretadas.

El cocinero reconoce que la decisión de convertir elBulli en una fundación era sólo una de las tres posibles y entre ellas, estaba la de cerrarlo definitivamente. Sin embargo, asegura que su compromiso con el mundo de la cocina es mucho más importante. Y la presión, como pudo comprobar tras la noticia confusa de The New York Times, era muy fuerte.

Además del adelanto de la decisión sobre el futuro de elBulli, del esfuerzo de comunicación del chef para desmentir la noticia viral del cierre definitivo, así como la decisión tomada con respecto al futuro de su restaurante, Adrià se ha visto obligado a hacer otro desmentido en torno a una de las afirmaciones recogidas en el post de The New York Times. Se trata de las pérdidas de su restaurante. El periodista estadounidense indicaba, poniendo como fuente al propio Adrià, que las mermas eran de medio millón de euros anuales. Sin embargo, el cocinero asegura que se trata de otro error y que esa cifra es el coste que le supone mantener su centro de investigación.

En un primer momento, tuvo que centrarse comunicativamente en el desmentido del cierre y en la creación de la Fundación. Así que, la aclaración acerca de esta cifra apareció un mes después, durante una conferencia de prensa ofrecida en Barcelona el 14 de abril y otra, el 15 de abril. Sin embargo, esta aclaración apenas ha sido recogida por los medios de comunicación y su visibilidad en Internet ha sido relativa, probablemente porque el chef tampoco desvela la cifra de pérdidas (Fernández, 2010). 
La fortaleza mediática de Ferran Adrià ha sido su trato personal con los medios de comunicación. No cuenta con un gabinete de comunicación y es conocido entre los periodistas como una persona accesible, que siempre ha estado dispuesto a ofrecer entrevistas. Sin embargo, esta cualidad no ha sido suficiente para hacer frente a una situación de información viral.

Los periodistas que reprodujeron el efecto viral no contactaron con la fuente para contrastar la información. Hay que tener en cuenta que la noticia se produjo en fin de semana y el despacho del chef estaba cerrado. Tampoco se le podía localizar en el restaurante, ya que también estaba cerrado. Únicamente se podía contactar con él a través del móvil y su número, probablemente, no estaba al alcance de muchos periodistas. Por ello, el desmentido lo tuvo que hacer el propio cocinero, contactando con la Agencia Efe y, además, a través de los periodistas especializados en gastronomía, quienes actuaron finalmente como los cortafuegos de la noticia viral.

El análisis de esta situación pone al descubierto que Ferran Adrià, pese a ser un gran valedor de Internet y de las nuevas tecnologías, y de seguir habitualmente la blogosfera, no cuenta, al contrario que gran parte de los grandes cocineros españoles, ni con un blog, ni con una cuenta de Twister, ni con un perfil en alguna red social, desde donde hubiese conseguido que su desmentido fuese riguroso y que su distribución fuese mucho más rápida en toda la red y, por ende, en todo el mundo.

No obstante, la noticia del desmentido consiguió una gran repercusión gracias a que el cocinero aportó un nuevo dato: elBulli se convertiría en una fundación. El cocinero se vio forzado por la presión mediática a adelantar esta noticia y no era la primera vez que le ocurría. Según Adrià, el anuncio del cierre que hizo en enero, también fue producto de la presión.

Él ya había dicho que se produciría un cambio y se vio forzado a anunciar el cierre durante dos años de elBulli, antes de lo previsto para evitar las conjeturas. Había anunciado, dos años antes, que habría un replanteamiento y con el anuncio, evitaba las especulaciones que se empezaban a generar en todo el mundo. Con ocasión de la celebración de Madrid Fusión, el chef decidió hacer pública la decisión tomada por él y su socio, Juli Soler. De esta manera, asegura Adrià, aprovechando la masiva presencia de medios de comunicación de todo el mundo, evitaba contarlo uno a uno. Sin embargo, afirma: "Nunca pesé que fuera a generarse un efecto igual". 


\section{El eco mediático del cierre temporal de elBulli}

El eco del efecto Adrià se ha mantenido en la prensa. Tras los anuncios del cierre y de la creación de la fundación, la prensa ha conservado la tensión informativa sobre el cocinero y todas sus acciones. Así, el 3 de marzo aparece en la prensa nacional e internacional nuevamente. En esta ocasión, debido a que ha sido elegido por el Gobierno de España, embajador del Turismo Español. En este nuevo papel, Adrià se estrenó en Londres.

También la prensa se hizo eco del anuncio de los cursos que impartirá, junto a cocineros españoles, en Harvard para estudiantes de Ciencia. Se publicó en las ediciones digitales y en papel, de todos los diarios españoles, el 22 y el 23 de marzo de 2010.La nueva era Adrià se estrenó con otros proyectos vinculados con la alimentación hospitalaria y su compromiso por la divulgación de la gastronomía, que también tuvieron repercusión en prensa.

Además, los diarios han tomado al cocinero como fuente habitual de temas de actualidad. Fue uno de las personas que comentó la muerte del fundador de "Mensajeros de la Paz", Vicente Ferrer (El Periódico, 2010). También participó en un programa de Televisión Española (TVE), sobre las dificultades para los discapacitados. El reportaje, titulado "Capacitados", fue emitido el 14 de febrero de 2010, a las 21.30 horas.

Después, fue objeto de noticia su despacho, situado en un palacete en el centro de Barcelona, dentro de un reportaje ofrecido por la revista Fuera de Serie, del diario Expansión, el 12 de marzo de 2010. Además, en el periodismo gastronómico se estrena un género, la entrevista de perfil humano, en las que Adrià comparte con naturalidad la normalidad y la modestia que rige su vida. Este tipo de entrevistas se pueden ver en el Magazine de La Vanguardia de 21 de febrero de 2010, firmada por Cristina Jolonch, y en el Diario Vasco de 7 de marzo de 2010 firmada por Julián Méndez.

El cocinero volvió a ser foco de la prensa mundial el pasado 26 de abril, cuando la revista inglesa Restaurant anunció su lista anual de los 50 mejores restaurantes del mundo. Después de cinco años, el cocinero de Cala Montjoi dejaba de ser el número uno del mundo, desbancado por el danés René Redzepi, uno de sus alumnos. Éste había hecho prácticas con Adrià en 1998 y en más de una ocasión ha declarado que su restaurante, Noma, existe gracias a lo que aprendió en España. Sin embargo, la noticia no fue portada de los diarios. Aunque ocupó espacio en sus páginas de "Cultura", además de blogs y ediciones digitales. La noticia ha dado pie a diversas columnas de opinión y análisis, firmados mayoritariamente por periodistas especializados en gastronomía y críticos gastronómicos.

Sociedad Latina de Comunicación Social Facultad de Ciencias de la Información - Universidad de La Laguna Avenida César Marique, s/n; Campus de Guajara 38071 La Laguna, Tenerife (Islas Canarias - España) 


\section{Conclusiones y discusión}

Tras el análisis de un hecho noticioso de calado mundial, como es el cierre temporal de elBulli, se podría concluir que el medio Internet se está posicionando con mucha más fuerza que los medios tradicionales. Su credibilidad puede hacer cambiar el curso de una noticia, como se ha podido comprobar con la publicación de una información por parte de un blog asociado al periódico The New York Times.

En este caso debe destacarse que no se trata de un blog de un vulgar ciudadano sino de un periodista especializado en el tema y, quizás más importante, de un blog perteneciente al universo NYT, un medio prestigioso entre sus pares y una referencia para lectores de todo el mundo. Es decir, credibilidad de NYT, la autoridad del bloguero Andrew Ferren y la accesibilidad del blog Diner's journal han potenciado el efecto viral de la noticia.

Este proceso de expansión de una información, sea cierta y contrastada o no, funciona de la misma manera que el marketing viral, sólo que frente al marketing no son los usuarios únicamente los que expanden el mensaje, sino los propios periodistas. En ocasiones, debido a este procedimiento que se realiza con gran rapidez, la calidad de la información en Internet se resiente. Los medios, en ocasiones, se precipitan al publicar una información en aras de la inmediatez y dejan de comprobar las fuentes. Por ello, se pone en tela de juicio su profesionalidad y si se trata de una información no contrastada o falsa.

El punto de inflexión que convierte una noticia en información viral es la agencia de noticias, gracias a su credibilidad y reputación online y su potente poder de distribución.

Realizar una corrección de una información viral no contrastada o un cortafuegos informativo para evitar que se siga propagando una noticia falsa es un proceso complejo, pero posible. Aunque en este caso ha sido un personaje de fama mundial, como Ferran Adrià, el que lo ha hecho.

La clave del éxito del cortafuegos ideado por Ferran Adrià consistió en acompañar la rectificación de la información ofrecida por el blogger asociado al periódico The New York Times de una nueva información, como fue la de adelantar que elBulli se convertiría en una fundación internacional para la investigación y el desarrollo de la cocina de vanguardia.

Con este trabajo se constata también, que fue más efectivo actuar hablando con los periodistas tradicionales especializados en el tema, que requirir una corrección del blogger que fue el origen de la difusión de la noticia falsa.

Sociedad Latina de Comunicación Social Facultad de Ciencias de la Información - Universidad de La Laguna

Avenida César Marique, s/n; Campus de Guajara 38071 La Laguna, Tenerife (Islas Canarias - España) 


\section{Referencias bibliográficas}

Bacallao Pino, L.M. (2010): "Representaciones mediáticas de las redes sociales: un estudio de casos", en Revista Latina de Comunicación Social, 65, páginas 114 a 125. La Laguna (Tenerife): Universidad de La Laguna, recuperado el 2 de febrero de 2011, de http://www.revistalatinacs.org/10/art/887_UZaragoza/09_Lazaro_Bacallao.html DOI: 10.4185/RLCS-65-2010-887-114-125

Beck, U. (2008): ¿Qué es la globalización? Falacias del globalismo, respuestas a la globalización. Barcelona: Paidós Ibérica.

Bruns, A. (2003). Gatewatching, not gatekeeping: Collaborative online news. Media International Australia Incorporating Culture and Policy: Quarterly Journal of Media Research and Resources, 107, pp. 31-44.

Campos Freire, Francisco (2008): "Las redes sociales trastocan los modelos de los medios de comunicación tradicionales". Revista Latina de Comunicación Social, 63, páginas 287 a 293. La Laguna (Tenerife): Universidad de La Laguna, recuperado el 23 de abril de 2009, http://www.ull.es/publicaciones/latina/ 2008/23 34 Santiago/Francisco Campos.html DOI: 10.4185/RLCS-63-2008-767-287-293

Cebrián Herreros, M. (2008): "La Web 2.0 como red social de comunicación e información". Estudios sobre el Mensaje Periodístico, 14, Universidad Cumplutense de Madrid, pp. 345-361, recuperado el 1 de abril de 2009, de http://revistas.ucm.es/inf/11341629/articulos/ESMP0808110345A.PDF

Fernández, M. (2010): “Gastroeconomía. Blog de Marta Fernández Guadaño", en Expasión.com, $\quad$ España, 15 de abril: http://www.expansion.com/accesible/blogs/gastroeconomia/57/56663.html (consultado el 10 de diciembre de 2010).

García Jiménez, A. et al (2010): "Una aproximación al concepto de frontera virtual. Identidades y espacios de comunicación", en Revista Latina de Comunicación Social, 65. La Laguna (Tenerife): Universidad de La Laguna, páginas 214 a 221, recuperado el 1 de marzo de 2011 , de http://www.revistalatinacs.org/10/art2/894_Madrid/16_Antonio_Garcia_et_al.html DOI: 10.4185/RLCS-65-2010-894-214-221 
García Santamaría, J.V. (2010). Crisis del periodismo de fuentes. Las prácticas del periodismo en España en el accidente de Spanair, en Revista Latina de Comunicación Social, 65. La Laguna (Tenerife): Universidad de La Laguna, páginas 516 a 537 recuperado el 30 de marzo de 2011, de http://www.revistalatinacs.org/10/art3/916_UC3M/38_Santamaria.html DOI: 10.4185/RLCS-65-2010-916-516-537.

Gracia Arnaiz, M. (1996): Paradojas de la alimentación contemporánea. Barcelona: Icaria, Institut Català d'Antropologia.

Ianni, O. (2006): Teorías de la globalización. México, D.F.: Siglo XXI Editores.

Jaffe, J. (2005): Life after the 30-second spot: energize your brand with a bold mix of alternatives to traditional advertising. Hoboken: John Wiley \& Sons.

Kimmel, A.J. (2010): Connecting with consumers. Marketing for new marketplace realities. Oxford: Oxford University.

Kirby, J. (2006): "Viral marketing", en Justin Kirby \& Paul Marsden (eds.), Connected marketing: The viral, buzz and word of mouth revolution. Oxford: Butterworth-Heinemann.

Lévy, P. (2004). Inteligencia Colectiva. Disponible en http://inteligenciacolectiva.bvsalud.org/public/documents/pdf/es/inteligenciaColectiva.pdf

López-Galiacho, J.L. (2010): “El oligopolio catalán en los medios de comunicación españoles: un estudio longitudinal", en CIC Cuadernos de Información y Comunicación, 15. Madrid: Universidad Complutense de Madrid, páginas 219 a 249, recuperado el 27 de febrero de

2011 ,

de http://revistas.ucm.es/portal/modulos.php?name=Revistas2 Ultimo\&id=CIYC

Mateos Rodríguez, F. M. (2008): "Comunidad virtual, red social y entorno mediático de los diarios digitales regionales canarios", en Revista Latina de Comunicación Social, 63, páginas 253 a 264. La Laguna (Tenerife): Universidad de La Laguna, recuperado el 20 de septiembre de 2009 , de http://www.revistalatinacs.org/ 2008/20 27 virtual/Francisco Mateos.html DOI: 10.4185/RLCS-63-2008-764-253-264

Morris, M.\& Ogan, C. (1996). The Internet as Mass Medium. Journal of Communication, Volume 46, Issue 1, p. 39-50.

Noguera Vivo, J.M. (2010): "Redes sociales como paradigma periodístico. Medios españoles en Facebook", en Revista Latina de Comunicación Social, 65. La Laguna (Tenerife): Universidad de La Laguna, páginas 176 a 186, recuperado el 3 de marzo de

Sociedad Latina de Comunicación Social Facultad de Ciencias de la Información - Universidad de La Laguna Avenida César Marique, s/n; Campus de Guajara 38071 La Laguna, Tenerife (Islas Canarias - España) 
2011,

de

http://www.revistalatinacs.org/10/art/891 UCAM/13 JM Noguera.html

DOI: 10.4185/RLCS-65-2010-891-176-186

Padilla, G. (2010): "Los anuncios de cosméticos en las revistas femeninas: globalización de prototipos y valores", en VV.AA., El cuarto bios. Estudios sobre comunicación e información (Ed. G. Abril). Madrid: Editorial Complutense.

Reinoso, J. (2011): "República consumista china", en El País Semanal, Madrid, 27 de febrero, $\quad y \quad$ en ElPaís.com, Madrid: http://www.elpais.com/articulo/portada/Republica/consumista/china/elpepusoceps/201102 27elpepspor 8/Tes.

Rheingold, H. (1993). A Comunidade Virtual. Lisboa: Gradiva.

Sivera, S. (2008): Marketing viral. Barcelona: Editorial UOC.

Steger, M. (2010): Globalization. New York: Sterling Publishing.

Stiglitz, J.E. (2003): Los felices 90. La semilla de la destrucción. Madrid: Taurus.

Stiglitz, J.E. (2004): The roaring nineties: a new history of the world's most prosperous decade. New York: W.W. Norton \& Company.

Tapscott, D.; Williams, A.D. (2007): Wikinomics: como a colaboração em massa pode mudar o seu negócio. Rio de Janeiro: Nova Fronteira.

Violi, P. (2008): "Espacio público y espacio privado en la era de Internet", en CIC Cuadernos de Información y Comunicación, 13. Madrid: Universidad Complutense de Madrid, páginas 39 a 59, recuperado el 27 de febrero de 2011 , http://revistas.ucm.es/portal/modulos.php?name=Revistas2 Historico\&id=CIYC\&num=CIY $\underline{\mathrm{C} 080811}$

Wilson, R. (2005): "The Six Simple Principles of Viral Marketing”, en Marketing Today, 1 de febrero: http://library.softgenx.com/Children/marketing/ViralMarketing.pdf

\section{Forma de citar este artículo en bibliografías}

Acosta, Y.; Canavilhas, J. y Gosciola, V. (2011): "La información viral. Estudio del caso del cierre temporal de elBulli”, en Revista PANGEA, 2, páginas 47 a 68 . Red Académica Iberoamericana de Comunicación. Recuperado el _ de ___ de 2__ de: http://revistapangea.org 